\title{
AGENESIA UNILATERAL DE LAS ESTRUCTURAS DEPENDIENTES DEL CONDUCTO MESONÉFRICO. PRESENTACIÓN DE UN CASO
}

\author{
D. MUÑOZ VÉLEZ, R. GARCÍA-MIRALlES GRAVALOS, J.M. BENEJAM GUAL \\ Servicio de Urología. Fundación Hospital de Manacor. Manacor (Mallorca).
}

Actas Urol Esp. 27 (4): 312-316, 2003

\section{RESUMEN}

"AGENESIA UNILATERAL DE LAS ESTRUCTURAS DEPENDIENTES DEL CONDUCTO MESONÉFRICO. PRESENTACIÓN DE UN CASO"

El conducto mesonéfrico juega un papel fundamental en el desarrollo del sistema genitourinario. De él, derivarán directamente el uréter, el conducto deferente y las vesículas seminales. A su vez, el brote ureteral interaccionando con el blastema mesonéfrico inducirá su conversión hacia tejido renal. Se desconoce el origen de estas anomalías del desarrollo embrionario. En algunos casos, se atribuye cierto papel al gen responsable de la fibrosis quística (CFRT) por la estrecha relación entre la agenesia deferencial y la fibrosis quística. La ausencia de estas estructuras suele tener un curso silente. Con frecuencia, su hallazgo es casual al explorar los deferentes o tras una prueba radiológica. La principal herramienta diagnóstica es la sospecha clínica. El conocimiento de estas asociaciones es lo que conducirá al diagnostico del resto de estructuras ausentes. Por otra parte, es necesario tener presente que también se pueden dar de forma aislada y su posible asociación con otras anomalías o enfermedades no urológicas, en especial con la fibrosis quística, la enfermedad hereditaria más frecuente en la raza caucásica.

PALABRAS CLAVE: Conducto mesonéfrico. Conducto deferente. Agenesia renal. Fibrosis quística.

\section{ABSTRACT}

"UNILATERAL AGENESIS OF THE STRUCTURES DEPENDENT ON DEVELOPMENT OF MESONEFRIC DUCT. A CASE REPORT"

The mesonefric duct plays an essential role in the development of the genitourinary tract. From that duct derive structures as the ureter, the vas deferens and the seminal vesicles. Also, the ureteral bud interact with the mesonefric blastema and induce its conversion to renal tissue. The origin of these anomalies of the embrionary development is unknown. In some cases, mutations on the gene of the cystic fibrosis (CFRT) could play a role, assuming that there is a relationship between the congenital absence of the vas deferens and the cystic fibrosis. Usually, the absence of these structures has a silent course. Thus, the most important diagnostic factor is the clinical suspicion. The knowledge of this association can lead to the diagnosis of other congenital abnormalities. In addition, it is important to know that these anomalies could be present isolated as expression of other non-urological diseases, specially the cystic fibrosis, the most common hereditary disease between the Caucasian race.

KEY WORDS: Mesonefric duct. Vas deferens. Renal agenesis. Cystic fibrosis. 
$\mathrm{O}$ casionalmente, en la práctica clínica se produce el hallazgo de una anomalía urológica que por su curso silente ha pasado desapercibida, permitiendo el diagnóstico de otras malformaciones asociadas que pueden adquirir trascendencia clínica en un momento dado de la vida del paciente.

Presentamos el caso de un varón que acudió a la consulta solicitando la realización de una vasectomía. A partir del descubrimiento de la agenesia de uno de los conductos deferentes se diagnosticó la ausencia del resto de órganos derivados directa o indirectamente del conducto mesonéfrico. El urólogo debe tener presente esas potenciales asociaciones que pese a su rareza están bien documentadas en la literatura ${ }^{1-3}$.

\section{CASO CLÍNICO}

Varón de 38 años de edad, sin antecedentes de interés, que acudió a la consulta de urología solicitando la realización de una vasectomía. La exploración física reveló un sujeto normoconstituido, con pene, testes y epidídimos de tamaño y consistencia normales. Se palpaba claramente el conducto deferente derecho. No ocurría así con conducto deferente izquierdo que no se lograba palpar dentro del cordón espermático. El tacto rectal resultó anodino. Ante la sospecha de agenesia del conducto deferente se realizó una ecografía transrectal en la que no se visualizó la vesícula seminal izquierda. Una UIV (Fig. 1) reveló la ausencia completa del riñón izquierdo. Posteriormente, una RNM confirmó la ausencia de la vesícula seminal, del conducto deferente y del uréter izquierdos (Fig. 2). El paciente fue programado para vasectomía que se realizó sin incidencias en el lado derecho. Los seminogramas de control realizados a los tres meses de la intervención revelaron una azoospermia completa confirmando la sospecha clínica de agenesia deferencial asociada a agenesia renal y de la vesícula seminal homolateral. Se aconsejó a los familiares de primer grado del paciente (dos hijos, hermano varón y sendos hijos de éste) la realización de un estudio ecográfico, ante la potencial transmisión con carácter autosómico dominante de la agenesia renal, constatándose la presencia de ambos riñones en todos ellos. El test del sudor en el paciente fue asimismo negativo.

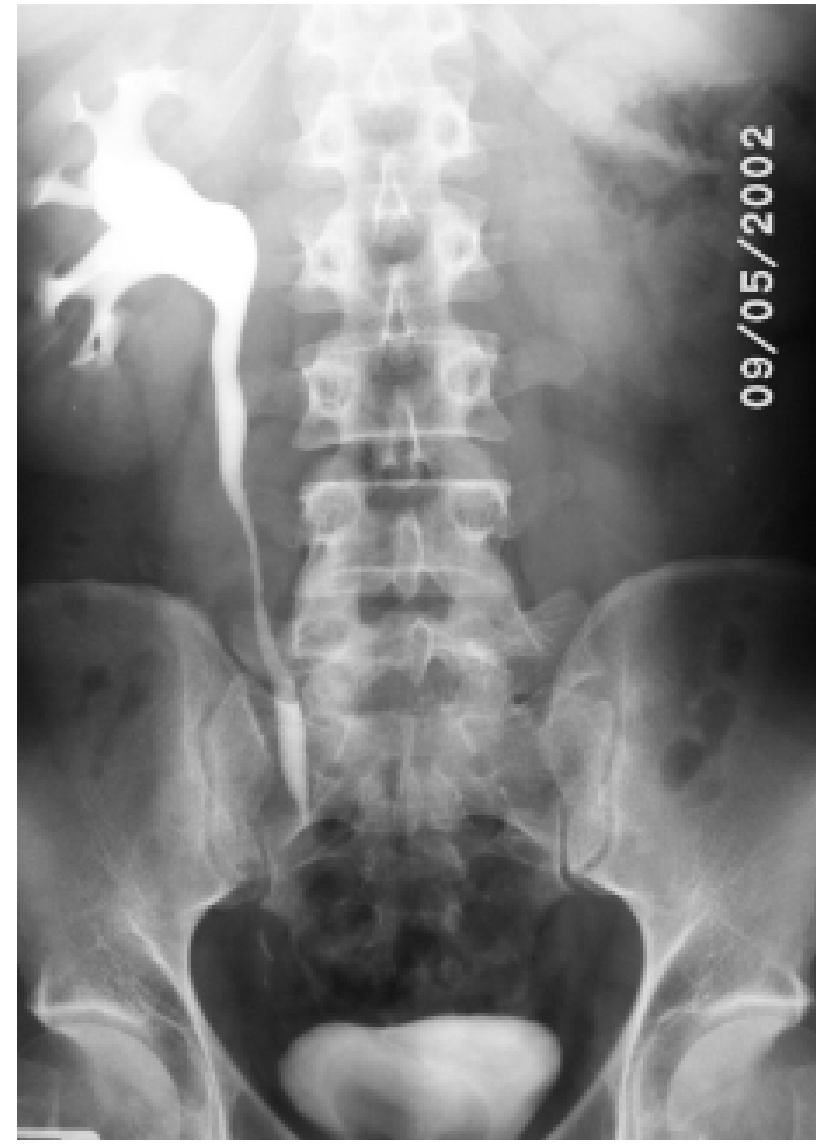

FIGURA 1. UIV donde se aprecia la ausencia completa de la unidad nefroureteral izquierda.

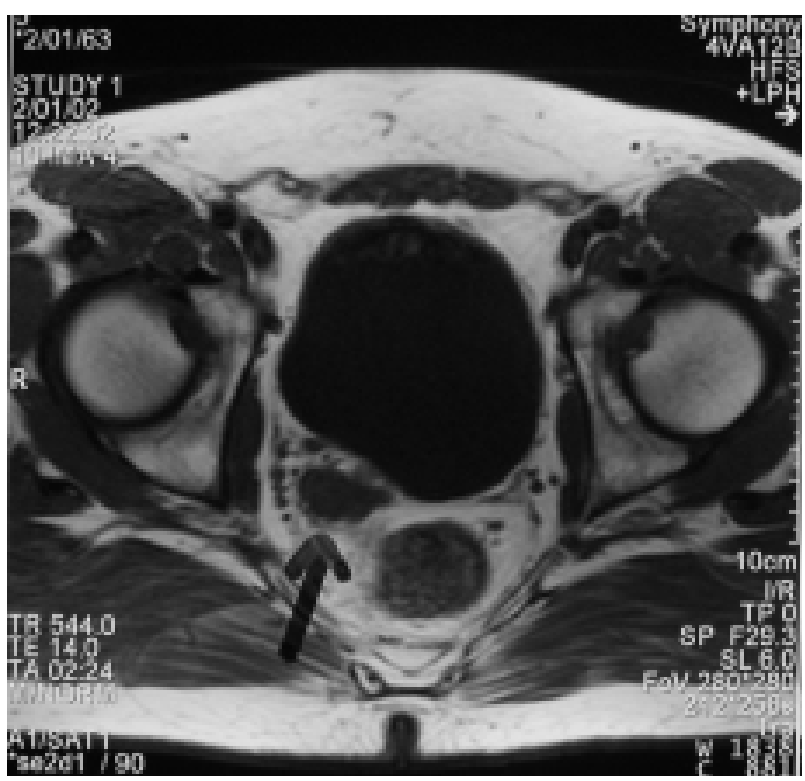

FIGURA 2. RNM en la que se identifica la vesicula seminal derecha (flecha) y la ausencia de la vesicula contralateral. 


\section{DISCUSIÓN}

De la porción más caudal del conducto mesonéfrico se formarán entre la $4^{\underline{a}}$ y la $13^{\underline{a}}$ semanas de gestación una serie de estructuras que darán lugar entre otros al uréter, el conducto deferente, las vesículas seminales y la próstata (Fig. 3). A su vez, el brote ureteral en su crecimiento craneal entra en contacto con el blastema mesonéfrico induciendo conversión de este en tejido renal, proceso que finaliza hacia las semanas 34 a $36^{4}$. La ausencia simultánea de todas estas estructuras resulta de la acción de una noxa durante la fase de desarrollo de estos órganos, bien de forma directa, o bien a través de los genes reguladores y/o de sus proteínas codificadoras. En ocasiones, estas estructuras están presentes pero de forma muy rudimentaria como es el caso de los quistes de las vesículas seminales o la atresia ureteral ${ }^{4}$.

La agenesia congénita del conducto deferente se ha descrito en el $1 \%$ de los varones infértiles y en el $0,5 \%$ de las autopsias ${ }^{5}$. Entre los varones que consultan por infertilidad es más frecuente la forma bilateral en una proporción de 4,5:16,7. Entre las formas unilaterales existe un ligero predominio del lado izquierdo. La agenesia congénita del conducto deferente se ha relacionado con mutaciones en el gen regulador de la conductancia transmembrana de la fibrosis quística (CFRT), localizado en el brazo largo del cromosoma $7(7 q)^{8}$. La fibrosis quística está considerada como la enfermedad hereditaria mortal más frecuente entre la raza blanca. Aproximadamente el 3\% de la población blanca es portadora de esta alteración genética que se transmite de forma autosómica recesiva. El 30\% de los pacientes son diagnosticados en la edad adulta ${ }^{9}$. Las mutaciones en el gen codificador de la proteína CFRT pueden dar lugar a las formas típicas de fibrosis quística, o bien a las llamadas formas atípicas, con frecuencia oligo o monosintomáticas como es la agenesia de los conductos deferentes. Esta relación entre la agenesia deferencial y las mutaciones en el gen CFRT es más acentuada entre las formas bilaterales que entre las unilaterales ${ }^{10}$.

Con frecuencia, la agenesia deferencial se acompaña de agenesia renal. La asociación entre la agenesia deferencial y la agenesia renal se da más a menudo entre las formas unilaterales y en proporciones variables $^{11,12}$. Se ha especulado que el mecanismo responsable de la agenesia deferencial es diferente cuando se presenta de forma aislada de cuando se acompaña de anomalías renales. Autores como Schlegel y Augarten no encontraron mutaciones en el gen CFTR en aquellos casos en los que la agenesia del conducto deferente se acompañaba de agenesia renal, por lo que la implicación del gen responsable de la fibrosis quística en casos como el que hemos expuesto es bastante improba$b^{7,13}$. Sin embargo, estudios más recientes han demostrado la presencia de mutaciones en el gen CFRT en aproximadamente un $31 \%$ de pacientes con agenesia deferencial y anomalías renales ${ }^{6}$.

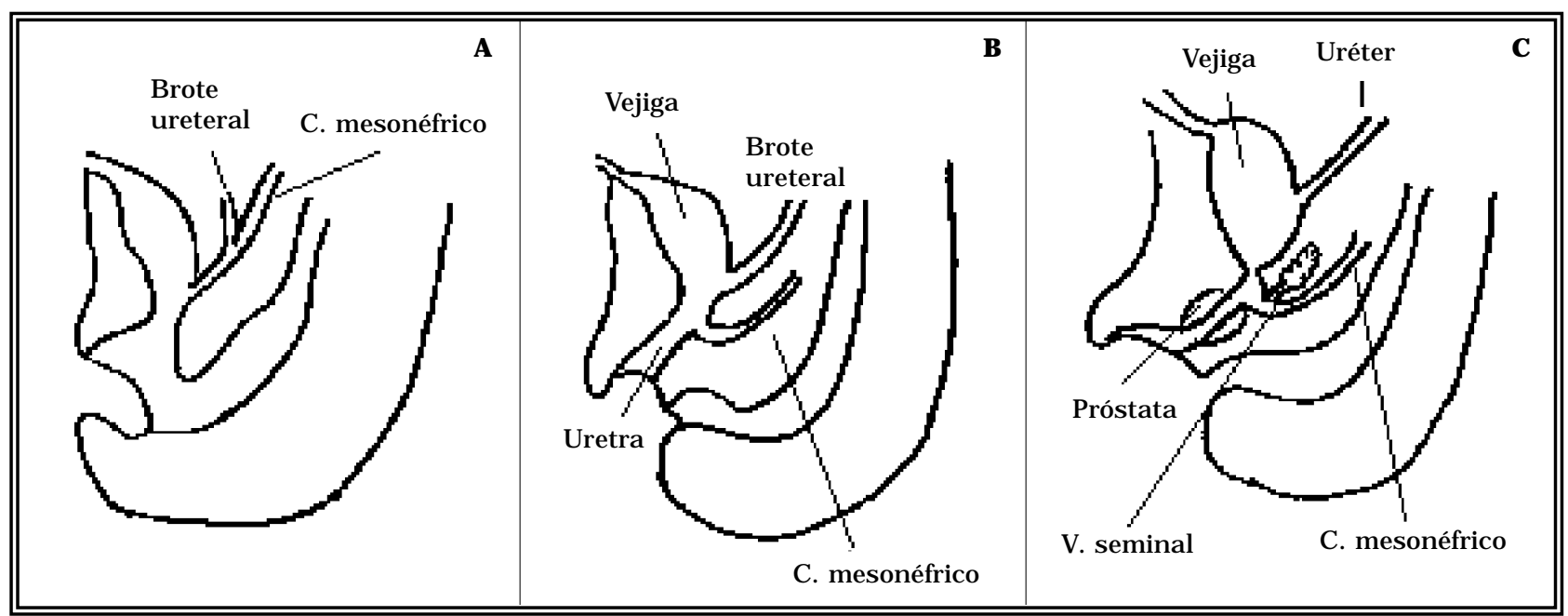

FIGURA 3. Diferentes fases del desarrollo embriológico del conducto mesonéfrico. A) $4^{a}$ semana. Formación del brote ureteral. B) $8^{a}$ semana. El brote ureteral se independiza del cdto mesonéfrico. C) $13^{a}$ semana. Formación de las vesiculas seminales. 
La agenesia renal unilateral predomina en el lado izquierdo y es más frecuente en el varón. Cerca de la mitad de estos pacientes presentaron en la edad pediátrica otras anomalías urológicas asociadas, principalmente reflujo vesicoureteral, estenosis de la unión urétero-vesical o a nivel de la unión pieloureteral ${ }^{14}$. Desde el punto de vista embriológico, su origen radica en un defecto en el brote ureteral que surge como una yema del conducto mesonéfrico hacia la $4^{\text {a }}$ semana de gestación y cuya ausencia o falta de desarrollo impide la maduración del blastema metanéfrico a tejido renal adulto. Se ha descrito en este defecto una transmisión autosómica dominante (HAD) con una penetrancia del $50 \%{ }^{15}$.

Las vesículas seminales se forman a partir de la semana $13^{a}$ de gestación como unos pequeños brotes en el conducto mesonéfrico del cual ya se ha separado el brote ureteral quedando convertido en conducto deferente. La agenesia deferencial no conlleva necesariamente la agenesia de las vesículas seminal, aunque cuando junto al deferente está ausente el uréter, lo más habitual es que las vesículas seminales tampoco se desarrollen ${ }^{16}$.

No existe ningún síntoma específico que pueda orientar hacia la ausencia de las estructuras derivadas del conducto mesonéfrico. Por tanto, la mejor herramienta diagnóstica es la sospecha clínica. La ausencia del conducto deferente durante la exploración física, o la monorenia no quirúrgica descubierta en el curso de una prueba radiológica deben alertar al médico sobre esta posibilidad. En estos casos, es aconsejable la realización de un seminograma, una ecografía o UIV para descartar la agenesia renal y la prueba del sudor para descartar la fibrosis quística ${ }^{11}$.

En ocasiones, unas rudimentarias vesículas o quistes seminales pueden dar lugar a una sintomatología irritativa en forma de disuria, polaquiuria o dolor perineal. En la mayoría de estos pacientes, el quiste de la vesícula seminal suele ser palpable o visible radiológicamente. De persistir la sintomatología, la exéresis quirúrgica del quiste seminal consigue resolver el cuadro en la mayoría de los $\operatorname{casos}^{17}$.

Radiológicamente, en los casos de agenesia renal, la radiografía simple no muestra ningún signo específico, aunque la medialización de los ángulos esplénico o hepático del colon pueden hacer sospechar su presencia. La ecografía o la urografía confirmarán el diagnóstico.

Para el diagnóstico de la agenesia de la vesícula seminal es de gran utilidad la ecografía transrectal. En casos de duda, la tomografía computerizada o la resonancia magnética puede servir de ayuda sin tener que recurrir a métodos más invasivos como la deferento-vesiculografía seminal.

La cistoscopia puede revelar la existencia de un trígono asimétrico o un hemitrígono, lo que sugiere una atresia ureteral parcial o completa junto a una agenesia renal ${ }^{18}$.

La fibrosis quística se puede descartar mediante la prueba del sudor o test de pilocarpina que mostrará una elevación de la concentración de cloro en el sudor. Un test del sudor positivo aconsejaría un estudio genético para conocer si el paciente es portador del gen de la fibrosis quística.

En cuanto a la repercusión de estas anomalías en la capacidad reproductora del varón, cuando éste no es portador del gen de la fibrosis quística, no está documentado que ésta se encuentre disminuida en tanto que las estructuras reproductoras contralaterales sean normales. Los pacientes subfértiles con agenesia unilateral del deferente que deseen recurrir a técnicas de reproducción asistida deberían someterse, tanto el varón como la mujer, a un estudio genético para descartar que sean portadores del gen CFTR ${ }^{19}$.

De la misma manera, la agenesia renal no tiene por qué repercutir en la calidad de vida del paciente. Es necesario tenerla presente ante cualquier proceso que afecte a la única unidad renal funcionante. Las recomendaciones generales serían las de evitar actividades físicas o deportes de riesgo a fin de reducir el riesgo de traumatismo sobre el riñón único, especialmente en los niños en los cuales el riñón dispone de una menor protección.

El pronóstico de la fibrosis quística dependerá en gran medida de la afectación pulmonar y de la instauración de un tratamiento precoz que evite la aparición de lesiones irreversibles.

Por último, también hay que tener presente la posibilidad de que coexistan otras malformaciones congénitas fundamentalmente cardiovasculares, digestivas, auditivas o musculoesqueléticas. 


\section{CONCLUSIONES}

- Las anomalías del desarrollo urogenital, aunque poco frecuentes, han de ser tenidas en cuenta pues pueden pasar desapercibidas hasta la edad adulta.

- La agenesia del conducto deferente uni o bilateral puede ser una forma de presentación atípica de la fibrosis quística.

- La agenesia deferencial en un elevado porcentaje de pacientes se acompaña de otras anomalías tanto genitourinarias como extraurinarias que es preciso descartar.

- El principal factor diagnóstico de la asociación de estas malformaciones es la sospecha clínica.

\section{REFERENCIAS}

1. SOLER FERNÁNDEZ JM, DOMÍNGUEZ BRAVO C, CABELLO PADIAL J, MURILLO MIRAT J, TORRUBIA ROMERO JF.: Quiste de vesícula seminal y agenesia renal ipsilateral: una asociación frecuente. Actas Urol Esp 1992; 16: 800-804.

2. PELLICÉ I VILALTA C, PARES I PUNTAS ME, BASSA I MASSANAS P.: Agenesia unilateral deferencial. Asociación conjunta a una ausencia de epidídimo, vesícula seminal y unidad renal del mismo lado. Caso sucinto. Actas Urol Esp 1998; 22: 454-457.

3. DOMÍNGUEZ FREIRE F, LÓPEZ BELLIDO D.: Agenesia unilateral de conducto deferente, un signo clínico útil en el diagnóstico de malformaciones genitourinarias. Actas Urol Esp 2001; 25: 770-773.

4. MAIZELS M.: Desarrollo normal del tracto urinario. Campbell Urología. 6 ${ }^{\mathrm{a}}$ Ed. Panamericana. Buenos Aires 1994; 2 (32): 1300-1341.

5. WAGENKNECHT LU, LOTZIN CF, SOMMER HJ.: Vas deferens aplasia: clinical and anatomical features of 90 cases. Prog Reprod Biol Med 1985; 12: 162-166.

6. CASALS T, BASSAS L, EGOZCUE $\mathrm{S}$ et al.: Heterogeneity for mutations in the CFTR gene and clinical correlations in patients with congenital absence of the vas deferens. Hum Reprod 2000 jul; 15 (7): 1476-1483.

7. SCHLEGEL PN, SHIN D, GOLDSTEIN M.: Urogenital anomalies in men with congenital absence of the vas deferens. J Urol 1996; 155 (5): 1644-1648.
8. STUHRMANN M, DORK T.: CFRT gene mutations and male infertility. Andrologia 2000; 32 (2): 71-83.

9. VARIOS AUTORES.: Fibrosis quística. En Manual Merck. Harcourt Editores, Madrid. 10 ${ }^{\underline{a}}$ Ed. (267): 2372-2376.

10. PATRIZIO P, ZIELENSKI J.: Congenital absence of the vas deferens: a mild form of cystic fibrosis. Mol Med Today 1996 jan; 2 (1): 24-31.

11. WEISKE WH, SALZLER N, SCHROEDER-PRINTZEN I, WEIDER W.: Clinical findings in congenital absence of the vasa deferentia. Andrologia 2000; 21 (1): 13-18.

12. DONOHUE RE, FAUVER HE: Unilateral absence of the vas deferens. A useful clinical sign. JAMA 1989 feb 24; 261 (8): 1180-1182.

13. AUGARTEN A, YAHAV Y, KEREM BS et al.: Congenital bilateral absence of vas deferens in the absence of cystic fibrosis. Lancet 1994 nov 26; 344 (8935): 1473-1474.

14. CASCIO S, PARAN S, PURI P.: Associated urological anomalies in children with unilateral renal agenesis. J Urol 1999; 162: 1081-1083.

15. DORAY B.: Genet Couns 1999; 10 (3): 251-257.

16. GOLDSTEIN M, SCHLOSSBERG S.: Men with congenital absence of the vas deferens often have seminal vesicles. $J$ Urol 1988; 140: 85-86.

17. VAN DEN OUDEN D, BLOM JH, BANGMA C, DE SPIEGELEER AH.: Diagnosis and managemente of seminal vesicle cysts associated with ipsilateral renal agenesis: a pooled analysis of 52 cases. Eur Urol 1998; 33 (5): 433-440.

18. LLOPIS MINGUEZ B, FERRUTXE FRAU J, MORENO PARDO B, BAIXAULI MARTÍNEZ JM, MORENO BARRACHINA E, RODRÍGUEZ HERNÁNDEZ JH.: Quiste de vesícula seminal asociado a agenesia renal, uréter ipsilateral y hemitrígono. Aportación de un caso. Arch Esp Urol 1979; 32: 529-540.

19. LEWIS-JONES DI, GAZVANI MR, MOUNTFORD R.: Cystic fibrosis in infertility: screening before assisted reproduction: opinion. Hum Reprod 2000; 15: 2415-2417.

Dr. D. Muñoz Vélez

C/ Cali, 6 - ptal. 3, 3ㅇ B

07006 Palma de Mallorca (Baleares)

(Trabajo recibido el 24 julio de 2002) 